\title{
Preparation and Electromagnetic Shielding Effectiveness of Metal Fibers/Polymer Composite
}

\author{
Wang Jianzhong, Ma Jun, Zhi Hao, Tang Huiping \\ State Key Laboratory of Porous Metal Materials, Northwest Institute for Nonferrous Metal Research, Xi'an 710016, China
}

\begin{abstract}
Composite containing metal fibers are applied widely in the field of electromagnetic interference for its excellent electromagnetic shielding effectiveness (EMSE). In the present study, two kinds of composite, 316L fibers/epoxy resin composite and $\mathrm{Cu}$ fibers/epoxy resin composite, were achieved using infiltration and mechanical stirring, respectively, The EMSE of the composite was assessed. The results show that the EMSE of 316L fibers/epoxy resin composite increases gradually with the aspect ratio of fibers increasing from 200 to 1000 , while it decreases quickly with that from 1000 to 3000 . Furthermore, the EMSE of the composite increases gradually as the content of fibers increases from $10 \mathrm{wt} \%$ to $25 \mathrm{wt} \%$. Additionally, for the $316 \mathrm{~L}$ fibers/epoxy resin composite, the optimum parameters of 316L fibers are the diameter of $8 \mu \mathrm{m}$, the content of $25 \mathrm{wt} \%$ and the aspect ratio of 1000 , and the highest EMSE of the composite is about $-78 \mathrm{~dB}$. For the $\mathrm{Cu}$ fibers/epoxy resin composite, the optimum parameters of $\mathrm{Cu}$ fibers are the diameter of $120 \mu \mathrm{m}$ and the content of $2.0 \mathrm{wt} \%$.
\end{abstract}

Key words: composite; electromagnetic interference (EMI); metal fibers; epoxy resin; electromagnetic shielding effectiveness (EMSE)

In recent years, electric devices and communication instruments have been widely used, but they generate severe electromagnetic radiation, resulting in harmful effects on highly sensitive precision electronic equipment as well as the living environment for human beings ${ }^{[1-3]}$. Now, electromagnetic shielding is an effective method resolving electromagnetic interference (EMI) and electromagnetic pollution ${ }^{[4]}$, and great efforts have been made for the development of high performance electromagnetic shielding material ${ }^{[5]}$. The ideal electromagnetic shielding material is expected to absorb electromagnetic waves efficiently which is light, thin, and functional, and can be applied in a wide frequency range ${ }^{[6]}$.

Up to date, the shells of phones, computers, refrigerators, microwave ovens, television, and air-conditioners are made of polymers, but the polymers can't shield off electromagnetic radiation ${ }^{[4]}$. So, it is very imperative to prepare novel electromagnetic shielding polymers. However, polymers at present are filled with conductive fillers generating electromagnetic shielding effectiveness. Conductive fillers include mainly carbon-based fillers, such as carbon black ${ }^{[7]}$, carbon nanotubes ${ }^{[8-11]}$, carbon nanofibers ${ }^{[12]}$, mesoporous carbon $^{[13]}$, pyrolytic carbon $(\mathrm{PyC})^{[14]}$, graphene ${ }^{[15,16]}$, carbon fibers and nickel-coated carbon fibers ${ }^{[17]}$, metal powders ${ }^{[18]}$, stainless steel fibers ${ }^{[3,4,19]}$, copper wires ${ }^{[20]}$. But, for the polymer composite containing carbon-based fillers or metal powders, individual conductive fillers are randomly distributed inside the polymer matrix and are surrounded by the molecular chains of polymer, and the electrical conductivity of the material strongly depends on electron percolation between the separated filler particles. Therefore, a high content and good dispersion of carbon-based fillers or metal powders are usually required to make a conductive interconnected network in order to obtain excellent electromagnetic shielding effectiveness (EMSE) ${ }^{[5]}$. In addition, metal fibers would be used widely in the EMI field due to their excellent conductivity, corrosion resistance, antioxidation and high strength. However, the EMSE of the polymer composite containing metal fibers is low ${ }^{[3,19,21]}$, and the effects of the fibrous characterization on the EMSE have not been investigated so far.

$\overline{\text { Received date: December } 1}, 2015$

Foundation item: National Natural Science Foundation of China (51301141, 51134003); Youth Scientific Star Item of Shaanxi Province (2014KJXX-24)

Corresponding author: Wang Jianzhong, Ph. D., Senior Engineer, State Key Laboratory of Porous Metal Materials, Northwest Institute for Nonferrous Metal Research, Xi'an 710016, P. R. China, Tel: 0086-29-86231095, E-mail: wangjz20012001@163.com 
In the present study, two kinds of composite mixed by epoxy resin and stainless steel fibers or copper fibers were prepared by immersion and mechanical stirring processes, respectively. Through varying the content of metal fibers, the aspect ratio of metal fibers, the diameter of metal fibers, the composite with different structures was obtained. Subsequently, the EMSE of the two kinds of composite in the frequency range of $2.25 \sim 2.65 \mathrm{GHz}$ was analyzed and the shielding mechanism was also studied.

\section{Experiment}

In the study, two kinds of metal fibers, stainless steel fibers (316L) with the diameters of $8,20,28,50,100,200 \mu \mathrm{m}$ and copper ones with the diameters of $80,100,120,160 \mu \mathrm{m}$, were used as raw materials. Another two kinds of raw materials were the epoxy resin and the ethylenediamine.

The composite for resolving EMI was manufactured by mixing the metal fibers, the epoxy resin and the ethylenediamine and was described in detail as follows.

(1) Composite containing 316L fibers

Firstly, the $316 \mathrm{~L}$ fibers were cut into short fibers with different aspect ratios, including 200, 1000, 2000, 3000, and then the fiber felt was prepared by an air-laid process. The fiber felt was sintered at $1250{ }^{\circ} \mathrm{C}$ for $2 \mathrm{~h}$ to form porous metal fiber materials as shown in Fig.1. Secondly, the epoxy resin and the ethylenediamine were mixed together, and then the mixture was immersed into the porous metal fiber materials and solidified to form the composite ${ }^{[22]}$. Then, the final dimensions of the composite were $150 \mathrm{~mm} \times 150 \mathrm{~mm} \times 5 \mathrm{~mm}$ (length $\times$ width $\times$ height), as shown in Fig.2a. In the paper, the process was defined as the first process.

(2) Composite containing $\mathrm{Cu}$ fibers

Firstly, the $\mathrm{Cu}$ fibers were cut into short fibers with the aspect ratio of 200, and then the short fibers and the epoxy resin was mixed together using the ethylenediamine as a solidified agent by the mechanical stirring method. Secondly, the mixture was poured into a mold and solidified to form another composite, as shown in Fig.2b. Then, the final dimension of the composite was $\Phi 200 \mathrm{~mm} \times 5 \mathrm{~mm}$. In the paper, the process was regarded as the second process.

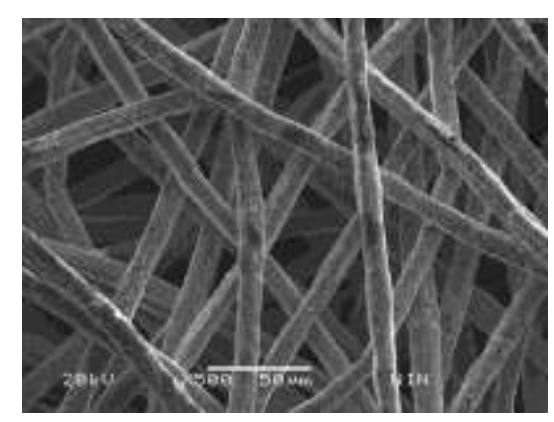

Fig.1 SEM image of porous metal fibers materials with the diameter of $8 \mu \mathrm{m}$

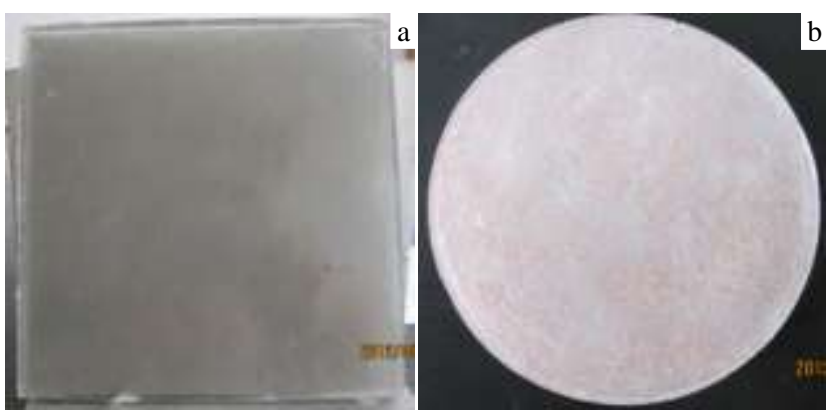

Fig.2 Images of composites made by two processes: (a) the first process and (b) the second process

Following the corresponding national standard of China (GJB 5313-2004), the EMSE of two kinds of composite was tested by a coaxial-waveguide network analyzer.

\section{Results and Discussion}

\subsection{Effect of the aspect ratio of metal fibers on EMSE}

When the content of the 316L fibers is $25 \mathrm{wt} \%$, the EMSE of the specimen made by the first process is affected by the aspect ratio of the fibers and the tested results are shown in Fig.3. It can be seen that the EMSE increases gradually with the aspect ratio increasing from 200 to 1000, while it decreases quickly with that from 1000 to 3000. Furthermore, the EMSE is the highest for the aspect ratio of 1000, about $-72 \sim-79 \mathrm{~dB}$, while it is the lowest for that of 3000 , about -58 $\sim-65 \mathrm{~dB}$. When the aspect ratio of the fibers is 1000 , the metal fibers can form an effective electric network in the polymer matrix ${ }^{[19]}$, leading to higher EMSE. However, when the aspect ratio is higher than 1000, the amount of the fibers decreases gradually per unit area as the aspect ratio increases, decreasing in the amount of crunode. As a result, the conductivity of the composite decreases and thus the EMSE decreases. Therefore, for the composite manufactured by the first process, the optimum aspect ratio of the $316 \mathrm{~L}$ fibers is 1000 .

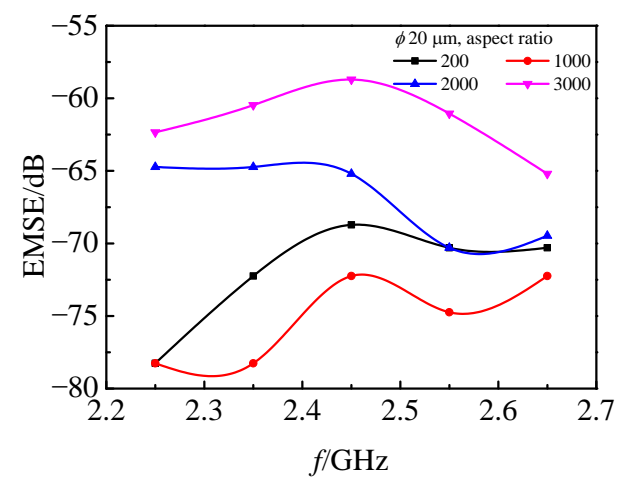

Fig.3 Effect of the aspect ratio of 316L fibers on the EMSE of the samples made by the first process at the same content of the fibers 


\subsection{Effect of the content of metal fibers on EMSE}

From the discussion of 2.1, we know that the appropriate aspect ratio of $316 \mathrm{~L}$ fibers is 1000 , so in the section, the samples are prepared by the first process using the aspect ratio of 1000 with different contents of fibers from $10 \mathrm{wt} \%$ to $30 \mathrm{wt} \%$ and the diameter of $8 \mu \mathrm{m}$, and then the measured results of EMSE are shown in Fig.4. It can be seen from Fig. 4 that at the identical electromagnetic wave frequency, the EMSE increases gradually as the contents increases from $10 \mathrm{wt} \%$ to $25 \mathrm{wt} \%$. Furthermore, the EMSE is about $-75 \sim-78 \mathrm{~dB}$ for the content of $25 \mathrm{wt} \%$ at the frequency of $2.25 \sim 2.65 \mathrm{GHz}$. In addition, the EMSE with the content of $25 \mathrm{wt} \%$ is appreciably lower than that of $30 \mathrm{wt} \%$. Hence, from the point of performance price ratio, in order to obtain excellent EMSE, the content of fibers may be $25 \mathrm{wt} \%$. It also can be seen from Fig. 4 that the EMSE exceeds $-40 \mathrm{~dB}$ when the content of fibers is higher than $10 \mathrm{wt} \%$. Moreover, the EMSE decreases firstly and arrives the minimum and then increases in the whole frequency when the content of fibers is lower than $20 \mathrm{wt} \%$, while the frequency has no significant influence on the EMSE when the content of fibers is higher than $25 \mathrm{wt} \%$.

The classical Schelkunoff formula for calculating the EMSE is defined as ${ }^{[23]}$ :

$$
\mathrm{EMSE}=A+R+M
$$

where $A$ is the absorption loss, $R$ is the reflection loss and $M$ is multiple reflection loss.

According to Eq.(1), the electrical surface resistivity of the composite decreases gradually with the contents of fibers increasing leading to the absorption loss, $A$, and the reflection loss, $R$, increasing slowly, so the EMSE increases gradually. But when the contents of fibers exceed the critical value, $A$ increases, while $R$ decreases. Consequently, the EMSE increases very slowly, or even decreases appreciably.

In addition, when the $316 \mathrm{~L}$ fibers are used as the conductive filler, they are not only conductor but also increase electromagnetic wave's scattering, bringing more interface than other organic fibers inside the composite. Furthermore, the composite forms an apparent layer structure as shown in Fig.5. It can be

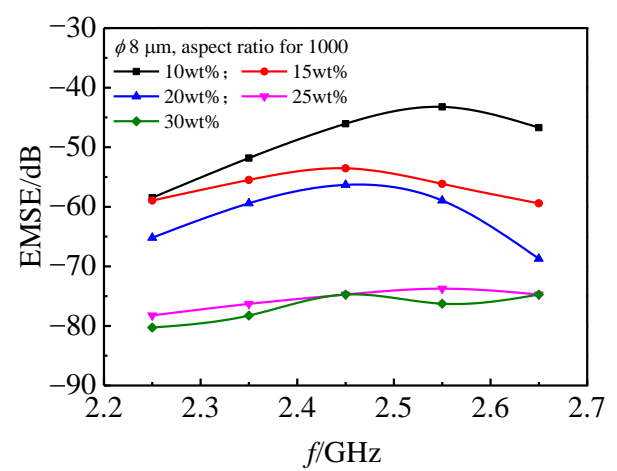

Fig.4 Effect of the contents of 316L fibers on the EMSE of the samples made by the first process at the same aspect ratio of the fibers

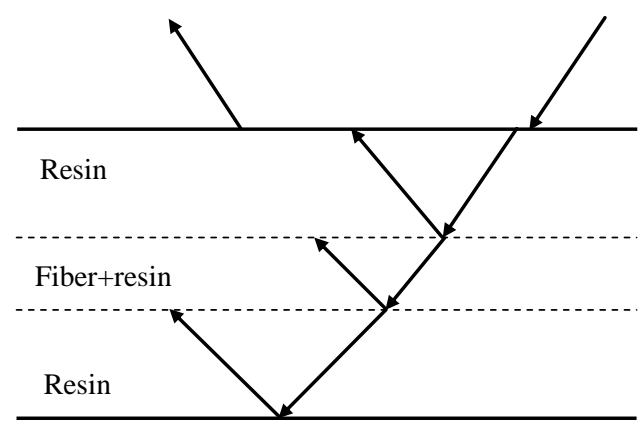

Fig.5 Sketch diagram of layer structure of the composite made by the first process

seen from Fig.5 that there are no conductive fibers at the surface layer and it is made up of pure epoxy resin. Therefore, both sides of the composite are non-conducting layers. But there are full of $316 \mathrm{~L}$ fibers in the core area, and the volume resistance here is much lower than any other parts. Hence the inner part of the composite can be considered as a conductive layer. As a matter of fact, such a layer structure changes the track of the incident electromagnetic wave and the wave will be scattered by four interfaces as shown in Fig.5. Such a structure will largely increase the EMSE of the composite (Fig.4).

Additionally, the effect of the contents of copper fibers with the diameter of $100 \mu \mathrm{m}$ and the aspect ratio of 200 on the EMSE of the composite made by the second process was also discussed, as shown in Fig. 6. It can be seen that the EMSE increases gradually as the contents of $\mathrm{Cu}$ fibers increase from $0 \mathrm{wt} \%$ to $2.0 \mathrm{wt} \%$, while it decreases appreciably with that increasing from $2.0 \mathrm{wt} \%$ to $2.5 \mathrm{wt} \%$. The EMSE is the highest, about $-20 \sim-25 \mathrm{~dB}$, when the content of $\mathrm{Cu}$ fibers is $2.0 \mathrm{wt} \%$, while it is the lowest without $\mathrm{Cu}$ fibers, about $-1.35 \sim-1.91 \mathrm{~dB}$. Therefore, for the composite prepared using the second process, the optimal content of $\mathrm{Cu}$ fibers is $2.0 \mathrm{wt} \%$.

In addition, it also can be seen from Fig. 6 that the EMSE of the composite is hardly affected by the electromagnetic wave frequency.

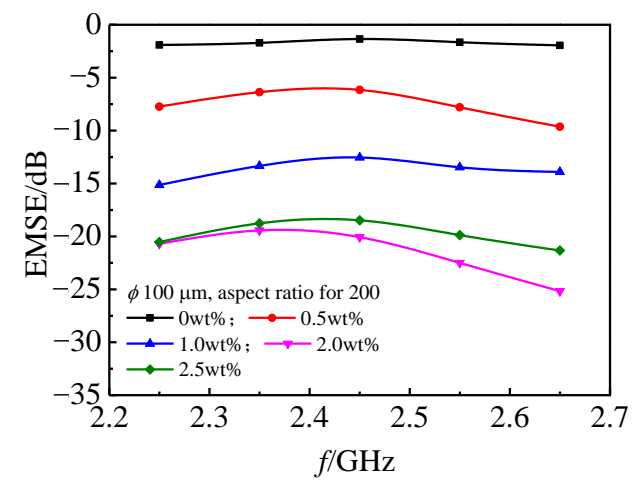

Fig.6 Effect of the contents of Cu fibers on the EMSE of the samples made by the second process at the aspect ratio of 200 


\subsection{Effect of the diameter of metal fibers on EMSE}

The effect of the diameters of 316L fibers on the EMSE of the composite fabricated by the first process, including diameters of $8,20,28,50,100,200 \mu \mathrm{m}$ with the aspect ratio of 1000 and the fibers content of $25 \mathrm{wt} \%$, was analyzed as shown in Fig.7. It can be seen that the EMSE of the composite with the fiber diameter of $8 \mu \mathrm{m}$ is stable, about $-74 \sim-78 \mathrm{~dB}$, but the EMSE of the composite with the fiber diameter of $20 \mu \mathrm{m}$ tends to fluctuate, about $-72 \sim-78 \mathrm{~dB}$, as the electromagnetic wave frequency increases. This may be caused by the difference between fiber diameters. For the diameters of 28, 50, 100, 200 $\mu \mathrm{m}$, the average EMSE decreases gradually with the diameter increasing, which is $-67.41,-64.55,-61.15$ and $-61.02 \mathrm{~dB}$, respectively. In addition, the EMSE of the composite made by the fibers of the diameter $8 \mu \mathrm{m}$ is scarcely affected by the electromagnetic wave frequency. So, in practice, the appropriate fiber diameter is $8 \mu \mathrm{m}$ to form the composite containing $316 \mathrm{~L}$ fibers using the first process.

For the composite containing $\mathrm{Cu}$ fibers, the effect of the diameters of fibers on the EMSE is shown in Fig.8. The composite is fabricated using the second process with the content of fibers of $0.5 \mathrm{wt} \%$ and the aspect ratio of 200 and the diameters of $80,100,120$, and $160 \mu \mathrm{m}$. It can be seen from Fig. 8 that the

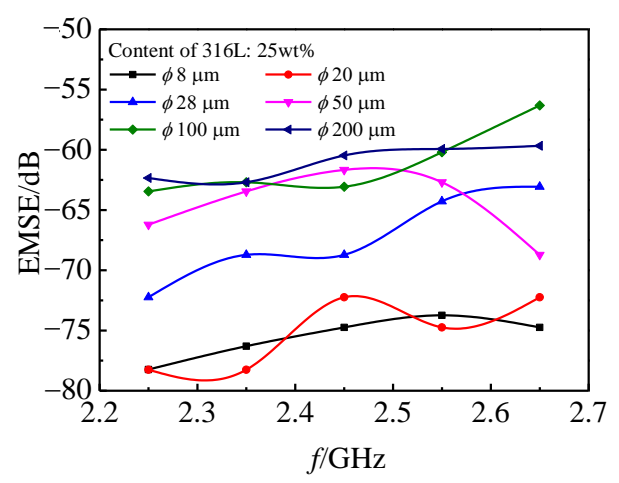

Fig.7 Effect of the diameters of 316L fibers on the EMSE of the samples made by the first process with the aspect ratio of fibers of 1000 and the fibers content of $25 \mathrm{wt} \%$

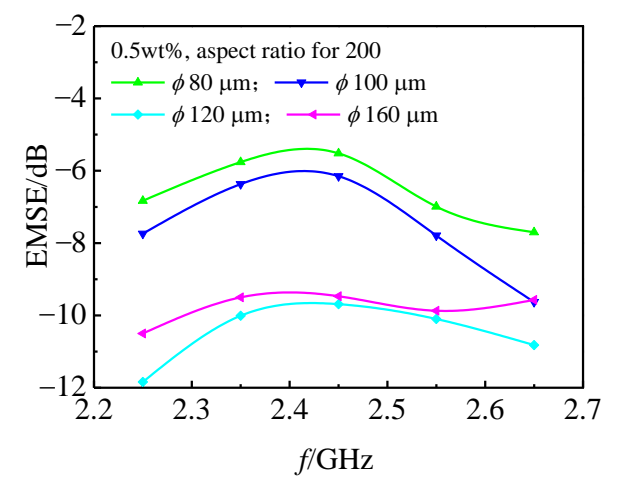

Fig.8 Effect of the diameters of $\mathrm{Cu}$ fibers on the EMSE of the samples made by the second process with the aspect ratio of fibers of 200 and the fibers content of $0.5 \mathrm{wt} \%$
EMSE increases gradually with the diameters increasing from $80 \mu \mathrm{m}$ to $120 \mu \mathrm{m}$ and the highest EMSE is about $-12 \mathrm{~dB}$, while it decreases appreciably when the diameter increases from 120 $\mu \mathrm{m}$ to $160 \mu \mathrm{m}$. Therefore, the appropriate fiber diameter is 120 $\mu \mathrm{m}$ to form the composite containing $\mathrm{Cu}$ fibers using the second process.

\section{Conclusions}

1) The EMSE of the composite containing 316L fibers increases gradually as the aspect ratio of fibers increases from 200 to 1000 , while it decreases quickly as that from 1000 to 3000 .

2) At the identical electromagnetic wave frequency, the EMSE of the composite increases gradually as the contents of metal fibers increase from $0 \mathrm{wt} \%$ to $2.0 \mathrm{wt} \%$ ( $\mathrm{Cu}$ fibers) or from $10 \mathrm{wt} \%$ to $25 \mathrm{wt} \%$ (316L fibers).

3) When the composite with excellent EMSE is fabricated using the first process, the appropriate parameters of $316 \mathrm{~L}$ fibers are the aspect ratio of 1000, the content of $25 \mathrm{wt} \%$ and the diameter of $8 \mu \mathrm{m}$ in practice. Furthermore, the highest EMSE is $-78 \mathrm{~dB}$.

4) When the composite is prepared by the second process, the appropriate parameters of $\mathrm{Cu}$ fibers are the content of 2.0 wt $\%$ and the diameter of $120 \mu \mathrm{m}$.

\section{References}

1 Dong J H. Study of Stainless Steel Fibers and Fabric Based on Anti-Radiation Properties[D]. Shijiazhuang: Hebei University of Science and Technology, 2012 (in Chinese)

2 Xu M, Bao H Q, Ma J R et al. Journal of Materials Science and Engineering $[\mathrm{J}], 2010,4: 92$

3 Shyr T W, Shie J W. Journal of Magnetism and Magnetic Materials[J], 2012, 324: 4127

4 Wang J Z, Xi Z P, Tang H P et al. Rare Metal Materials and Engineering[J], 2011, 40(9): 1688 (in Chinese)

5 Chen Z P, Xu C, Ma C Q et al. Advanced Materials[J], 2013, 25: 1296

6 Hung F S. Trans Nonferrous Met Soc China[J], 2013, 23(9): 2633

7 Im J L, Kim J G, Lee Y S. Carbon[J], 2009, 47: 2640

8 Song W L, Cao M S, Hou Z L et al. Scripta Materialia[J], 2009, 61: 201

9 Park S H, Theilmann P, Yang K Q et al. Applied Physics Letters[J], 2010, 96: 43115

10 Wang L L, Tay B K, See K Y et al. Carbon[J], 2009, 47: 1905

11 Fletcher A, Guptab M C, Dudley K L et al. Composites Science and Technology[J], 2010, 70: 953

12 Mohammed H A, Uttandaraman S. Carbon[J], 2009, 47: 2

13 Wang J C, Xiang C S, Liu Q et al. Advanced Functional Materials[J], 2008, 18: 2995

14 Hao X, Yin X W, Zhang L T et al. Journal of Materials Science \& Technology[J], 2013, 29: 249

15 Zhang H B, Yan Q, Zheng W G et al. Acs Applied Materials \& 
Interfaces[J], 2011, 3: 918

16 lecular Materials and Engineering[J], 2011, 296: 894

17 Tang P, Chen Z Z, Zhang R et al. Polymer Bulletin[J], 2013, 2: 46

18 Klemperer C J, Maharaj D. Composite Structures[J], 2009, 91: 467

19 Amarasekera J. Reinforced Plastics[J], 2005, 49: 38

20 Cheng K B, Ramakrishna S, Lee K C. Composites Part A,
Applied Science and Manufacturing[J], 2000, 31: 1039

21 Chen C S, Chen W R, Chen S C et al. International Communications in Heat and Mass Transfer [J], 2008, 35: 744

22 Wang J Z, Tang H P, Xi Z P et al. Preparation Method and Metal Fiber/Polymer Composite for Electromagnetic Shielding Thereof: Chinese Patent, CN, 102514290 A[P]. 2011 (in Chinese)

23 Zhang Y F, Hao W J, Zhang Z L. Electromagnetic Radiation Pollution and Protection[M]. Beijing: Metallurgy Industry Press, 2010 (in Chinese)

\title{
金属纤维/聚合物复合材料的制备及其电磁屏蔽效能
}

\author{
王建忠, 马 军, 支 浩, 汤慧萍 \\ (西北有色金属研究院 金属多孔材料国家重点实验室，陕西 西安 710016)
}

\begin{abstract}
摘 要: 填充金属纤维的复合材料由于具有优异的电磁屏蔽效能（EMSE）而广泛应用于电磁干扰领域。本研究采用浸渗和机械摚拌法 分别制备了 $316 \mathrm{~L}$ 纤维/环氧树脂和 $\mathrm{Cu}$ 纤维/环氧树脂 2 种复合材料, 并测试了其电磁屏蔽效能。研究表明, 当 $316 \mathrm{~L}$ 纤维长径比从 200 增加到 1000 时, $316 \mathrm{~L}$ 纤维/环氧树脂复合材料的电磁屏蔽效能逐渐增大, 而当长径比从 1000 增加到 3000 时, 其复合材料的电磁屏蔽效 能迅速下降; 当 $316 \mathrm{~L}$ 纤维的质量分数从 $10 \%$ 增加到 $25 \%$ 时, 复合材料的电磁屏蔽效能逐渐增大。对于 $316 \mathrm{~L}$ 纤维环氧树脂复合材料而 言, $316 \mathrm{~L}$ 纤维的最佳参数：纤维直径为 $8 \mu \mathrm{m}$ 、含量为 $25 \%$ 、长径比为 1000 , 其复合材料的电磁屏蔽效能最高可达 $-78 \mathrm{~dB}$ 。对于 $\mathrm{Cu}$ 纤 维/环氧树脂复合材料而言, $\mathrm{Cu}$ 纤维的最佳参数：纤维直径为 $120 \mu \mathrm{m}$ 、含量为 $2.0 \%$ 。
\end{abstract}

关键词: 复合材料; 电磁干扰 (EMI); 金属纤维; 环氧树脂; 电磁屏蔽效能 (EMSE)

作者简介：王建忠，男，1980 年生，博士，高级工程师，西北有色金属研究院金属多孔材料国家重点实验室，陕西 西安 710016，电 话: 029-86231095, E-mail: wangjz20012001@163.com 